\title{
Leaf and Root Growth in Relation to Water Status
}

\author{
Theodore C. Hsiao \\ Department of Land, Air and Water Resources, University of California, Davis, CA 95616-8628
}

Expansive growth of leaves of a plant defines the size of its canopy for capturing sunlight and carrying out photosynthesis. Expansive growth of roots defines the volume of soil that the plant explores for water and mineral nutrients. The two organs, however, compete for assimilates produced by the mature leaves, and for minerals and water. Yet they are coordinated in size, and their sizes relative to each other change dynamically in responses to environmental conditions, in a manner expected for the optimal utilization of assimilates and other resources (Wilson, 1988). How the coordination is achieved remains to be clearly delineated in spite of recent progress in our understanding of expansive growth. Here I outline and highlight some of the recent advances in the study of expansive growth in general, and address the possible mechanisms coordinating the growth of the two organs, with emphasis on the more physical aspects. In addition, the ecophysiological and practical implications of the dynamic changes in the relative growth of roots and leaves are outlined. I will be drawing heavily on our own work, so the review will be largely from a personal viewpoint, and does not pretend to be comprehensive.

\section{LOCKHART EQUATIONS}

Expansive growth may be defined as the irreversible enlargement of cells or organs. The enlargement refers specifically to the overall dimensions of the cell wall. A common way to view the more physical aspects of expansive growth is in terms of Lockhart equations (Lockhart, 1965). One equation of Lockhart expresses the rate of relative increase in volume of a cell as the product of its turgor pressure $\left(\psi_{\mathrm{p}}\right)$ above a minimal yield threshold turgor pressure $(\mathrm{Y})$ and a coefficient $\mathrm{m}$, termed volumetric extensibity:

$$
\frac{d V}{V d t}=m\left(\psi_{p}-Y\right)
$$

where $\mathrm{V}$ is the cell volume and $\mathrm{t}$ is time. Eq. [1] emphasizes the fact that $\psi_{\mathrm{p}}$ must be above the threshold value of $\mathrm{Y}$ for the cell to grow. Implicit in Eq [1] is the role of water potential $(\Psi)$ and solute (osmotic) potential $\left(\psi_{\mathrm{s}}\right)$ in determining $\psi_{\mathrm{p}}$, and the role of cell wall physical properties (plasticity), and, indirectly, metabolism, in determining $\mathrm{m}$ and $\mathrm{Y}$. Although there is often a tendency to view $m$ and $\mathrm{Y}$ as constants, it has long been recognized (Acevedo et al., 1971; Green, 1968; Green and Cummins, 1974) that they change in response to changes in water status of the growing organ. In fact, their changes provide additional means for the plant to adjust the growth of its organs to changes in water status (Hsiao et al., 1976).

To take into account the need for the continuous transport of water into the cell to maintain growth, Eq. [1] is combined with the standard equation for water transport in terms of the overall hydraulic conductance of the cell $(\mathrm{C})$ and the gradient of $\Psi$ driving the uptake, yielding:

$$
\frac{d V}{V d t}=\frac{m C}{m+C}\left(\Psi^{o}-\psi_{s}-Y\right)
$$

where $\Psi^{\circ}$ is $\Psi$ of the medium surrounding the growing cell or of the source of water, and _. .is solute potential within the cell. Clearly, when $\mathrm{C}>>\mathrm{m}, \mathrm{m}+\mathrm{C}$ becomes $\mathrm{C}$ and cancels the $\mathrm{C}$ in the numerator, and $\mathrm{Eq}$. [2] reverts to Eq. [1]. An illustration of a situation in which the simpler Eq. [1] instead of the more complicated Eq. [2] is adequate to describe growth is the case of cells in maize (Zea mays L.) roots bathed in a

\footnotetext{
Received for publication 15 Sept. 1999. Accepted for publication 18 Oct. 1999. This work was supported by Grants 91-37100-6671 and 96-35100-3200 of the NRI Competitive Grant Program, U.S. Dept. of Agriculture. I thank Tony Matista for his indispensable help in preparing this manuscript.The cost of publishing this paper was defrayed in part by the payment of page charges. Under postal regulations, this paper therefore must be hereby marked advertisement solely to indicate this fact.
}

flowing aqueous solution (Frensch and Hsiao, 1995). There C was assessed to be large relative to $\mathrm{m}$. On the other hand, studies have pointed to conductance as a major factor limiting growth of cells in the stem (hypocotyl) of soybean [Glycine $\max (\mathrm{L}$.) Murr.] seedling with roots in water-deficient vermiculite (Nonami and Boyer, 1990). In that case, the low conductance of the radial path between the xylem and the growing cells was attributed to a layer of small cells $\approx 200 \mu \mathrm{m}$ thick separating the ring of xylem vessels from the cortical and epidermal cells (Nonami et al., 1997).

For simplicity, the remaining part of this paper will discuss growth mostly in terms of the parameters in Eq. [1]. Conductance and $\Psi$ gradient will be mentioned, however, where relevant.

\section{RESPONSES OF EXPANSIVE GROWTH TO WATER STRESS}

In terms of growth physics and associated processes, more is known about roots than about leaves. Some of the more interesting recent results with roots are discussed first, followed by a brief review of results with leaves for comparison.

Growth of leaves has long been known to be highly sensitive to inhibition by water stress (Boyer, 1968). Root growth, on the other hand, is more resistant (Westgate and Boyer, 1985). This differential sensitivity is illustrated with some maize data obtained in our laboratory (Fig. 1). The leaf elongated at a maximal rate in the well-watered control, with $\Psi$ of the growth zone higher than $-0.8 \mathrm{MPa}$. Elongation was reduced when growth zone $\Psi$ was reduced by a few hundredths of a MPa, and stopped when $\Psi$ was reduced by $0.3 \mathrm{MPa}$, to a value of $-1.05 \mathrm{MPa}$ (Fig. 1B). For roots in vermiculite, elongation was also reduced by small reductions in medium $\Psi$ (Fig. 1A). Upon further reductions in $\Psi$, however, root elongation was less affected, and
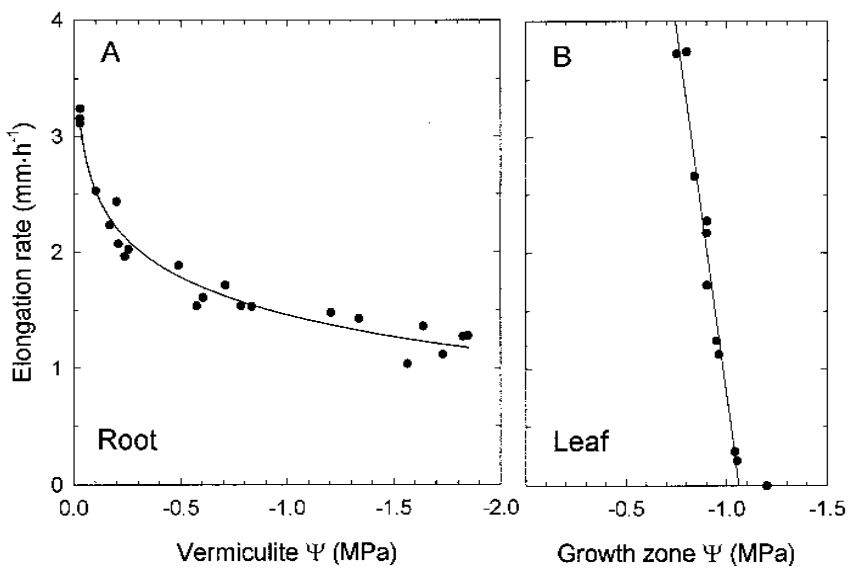

Fig. 1. Longitudinal growth of $\operatorname{root}(\mathbf{A})$ and leaf $(\mathbf{B})$ of maize at $29^{\circ} \mathrm{C}$ as affected by water potential $(\Psi)$. In $(\mathbf{A})$, etiolated maize seedlings were planted in well-moistened vermiculite in a constant temperature chamber, transferred to vermiculite wetted to the indicated $\Psi 30 \mathrm{~h}$ after planting, and the growth rate of their primary roots was measured after growth had become steady (ranging from $15 \mathrm{~h}$ for $\Psi=-0.03 \mathrm{MPa}$ to $48 \mathrm{~h}$ for $\Psi=-1.7 \mathrm{MPa}$ ). Modified from Sharp et al. (1988). In (B), maize seedlings were grown in a potting mixture in a controlled environment chamber until the fifth leaf emerged, then watering was withheld and elongation rate of the fifth leaf was monitored with a position transducer (linear variable differential transformer, LVDT). When elongation rate dropped to the desired level, segments $50 \mathrm{~mm}$ long encompassing the growth zone were excised from the base of the leaf, and $\Psi$ was measured by the Shardakov method at $5^{\circ} \mathrm{C}$, and $\psi_{\text {s }}$ by isopiestic thermocouple psychrometry at $29^{\circ} \mathrm{C}$ after freezing and thawing. Elongation rate was measured 10 to $15 \mathrm{~min}$ before excision. Modified from Hsiao and Jing (1987). 
continued at a reasonable rate even when medium $\Psi$ was reduced to $-1.9 \mathrm{MPa}$. Although this $\Psi$ level is $0.4 \mathrm{MPa}$ below the permanent wilting point $(-1.5 \mathrm{MPa})$, the rate of elongation was still more than one third of that of the well watered control (Fig. 1A). To gain insight as to the mechanism underlying the ability to grow under such low levels of medium $\Psi$, it is helpful to examine the dynamic changes when water stress is imposed suddenly.

In an early study, Acevedo et al. (1971) showed that upon a stepwise reduction in root medium $\Psi$ of $0.2 \mathrm{MPa}$, growth of leaves of maize stopped momentarily, then gradually resumed, reaching a steady rate about only one-half of the original rate. Later, Kuzmanoff and Evans (1981) found that roots of lentil (Lens culinaris Medik.) behaved similarly upon a stepwise reduction in medium $\Psi$, but the growth rate recovered fully over time in the low $\Psi$ medium. Even after a reduction of $0.7 \mathrm{MPa}$ in $\Psi$, lentil roots recovered to grow essentially at the full rate after 50 min of adjustment. How was this adjustment achieved in terms of the parameters in the Lockhart equation? Early evidence (Greacen and Oh, 1972; Hsiao et al., 1976; Meyers and Boyer, 1972) already indicated the importance of osmotic adjustment for the maintenance of turgor, at least partially, and hence expansive growth. More definitive data came from the use of a pressure microprobe to monitor changes in turgor pressure of roots of maize seedlings while growth was also being monitored during stepwise changes in medium water status (Fig. 2). When the medium $\Psi$ for the growing root was suddenly reduced from zero $\left(0.1 \mathrm{mM} \mathrm{CaCl}_{2}\right)$ to $-0.42 \mathrm{MPa}$ by

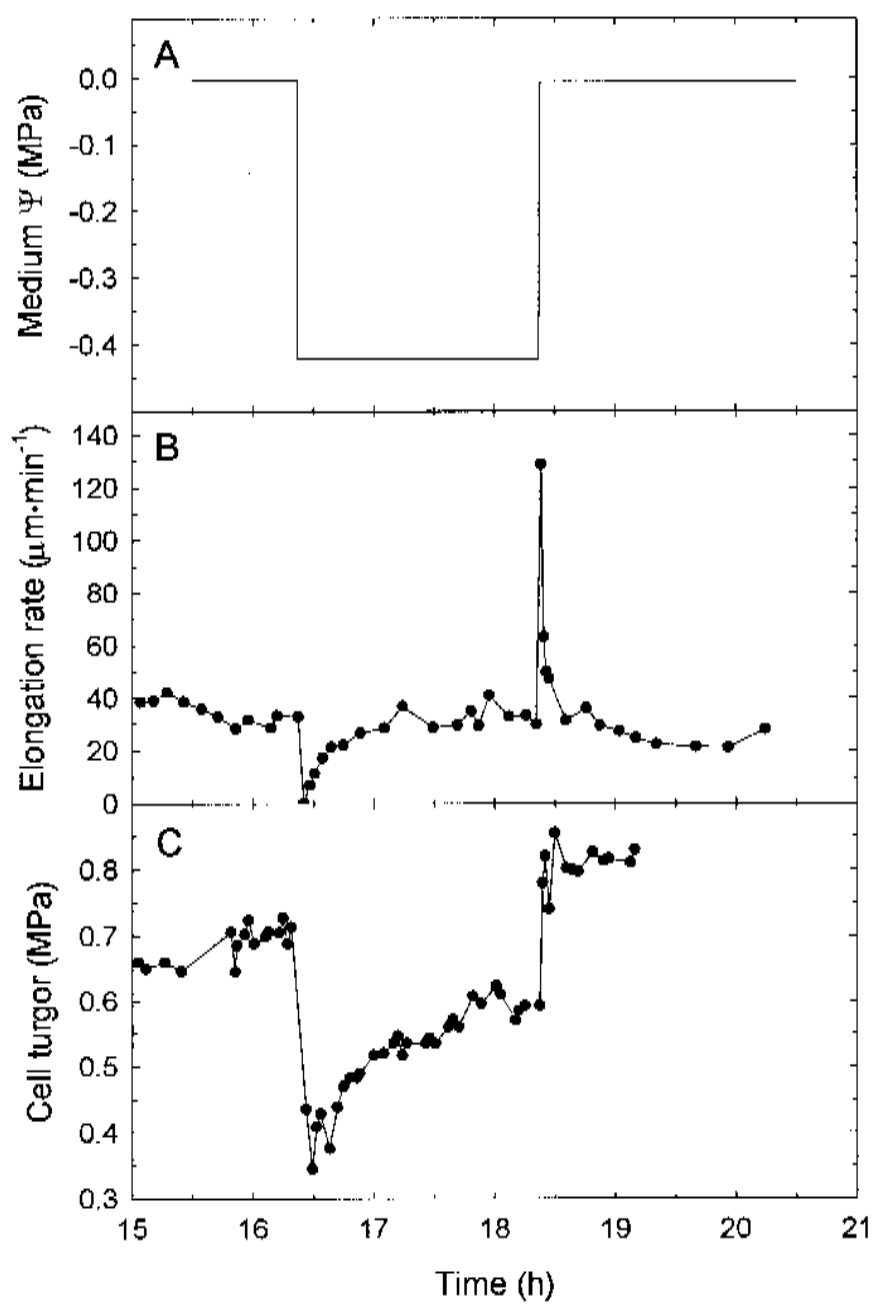

Fig. 2. Longitudinal growth rate and cell turgor of the primary root of etiolated maize seedling as affected by step-wise changes in medium $\Psi$. Growth was measured with LVDT. Cell turgor $\left(\psi_{\mathrm{p}}\right)$ was measured with a pressure microprobe in the region of maximum growth (4 to $5 \mathrm{~mm}$ from apex) with most of the points representing different cells. The medium bathing the root, initially $0.1 \mathrm{mM} \mathrm{CaCl}_{2}$, was changed to $-0.42 \mathrm{MPa}$ sorbitol in $0.1 \mathrm{~mm}$ $\mathrm{CaCl}_{2}$, and later back to $0.1 \mathrm{~mm} \mathrm{CaCl} 1_{2}$. From Hsiao and Jing (1987). changing to an osmotic solution (sorbitol in $0.1 \mathrm{mM} \mathrm{CaCl}_{2}$ ), turgor was reduced nearly proportionally, as quickly as could be measured, and growth stopped. Within minutes, turgor began to recover and growth resumed. The growth rate increased with time and recovered fully in $45 \mathrm{~min}$. Turgor, on the other hand, recovered only to a level $0.15 \mathrm{MPa}$ below the value before the imposition of water stress (Fig. 2). The results are consistent with the concept of yield threshold turgor and the need for turgor to rise above this threshold via osmotic adjustment for growth to resume. At the same time, the fact that growth under the stress had recovered fully while recovery in turgor was only partial showed that $\mathrm{Y}$, and probably $\mathrm{m}$, in the Lockhart equation must have adjusted to sustain the same growth rate at a reduced turgor.

After $2 \mathrm{~h}$ of stress the medium bathing the root was changed back to $0.1 \mathrm{~mm} \mathrm{CaCl}_{2}$. There was an immediate, steep increase in turgor, and a burst of growth (Fig. 2). After the initial burst, however, growth slowed to a level lower than that before stress, while turgor remained higher. Similar results were observed in other experiments when growth was suddenly accelerated several fold by a sudden increase in turgor. During the stress period, Y was apparently relatively high and the growth-effective turgor small. When stress was released, turgor was suddenly raised by $0.25 \mathrm{MPa}$, increasing the growth-effective turgor several fold, leading to the burst of growth. This abnormally high growth rate apparently was detrimental, and growth subsequently slowed in spite of the high turgor, which presumably involved shifts in $\mathrm{Y}$ and $\mathrm{m}$ in the direction opposite to the adjustment under water stress.

Green and Cummins (1974) had long emphasized the tendency of expansive growth to be self-stabilizing as conditions varied, especially

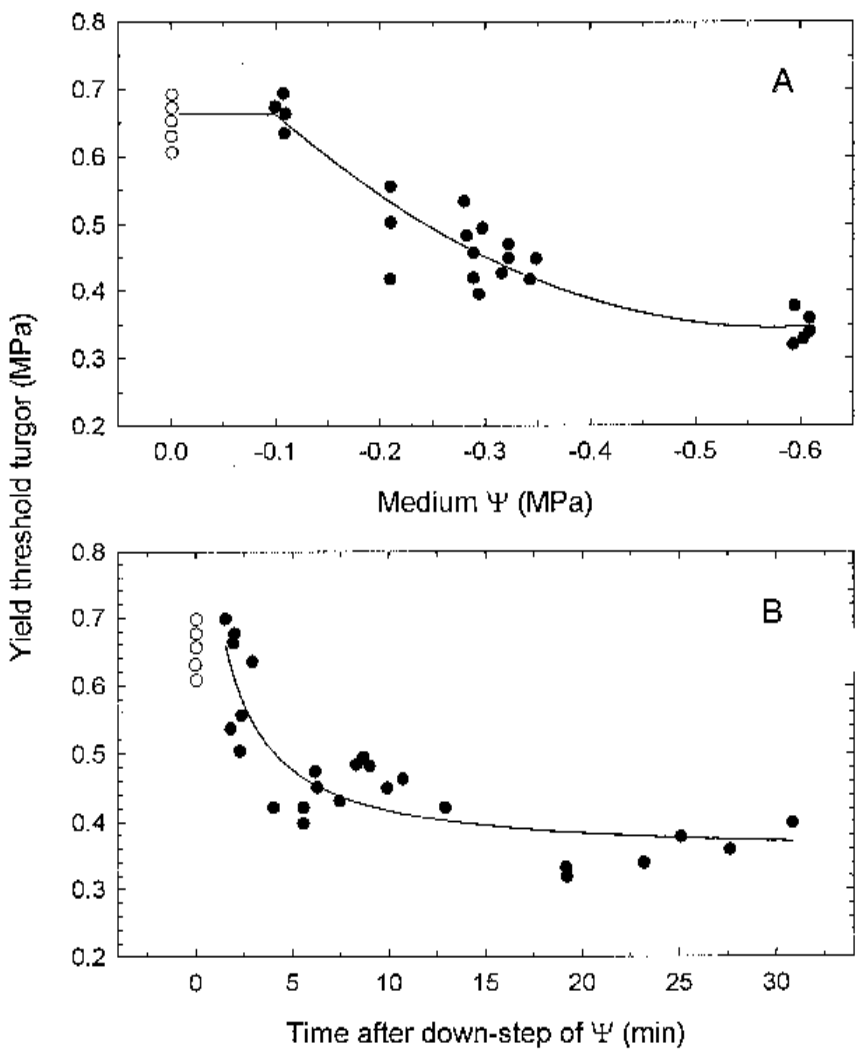

Fig. 3. Response of yield threshold turgor (Y) of cells in roots of maize seedlings to a step-wise reduction in medium $\Psi$. In (A), Y is shown as affected by changes in solute potential of the medium (either $\mathrm{KC} 1$ or manitol in $0.1 \mathrm{~mm}$ $\mathrm{CaCl}_{2}$ ) bathing the roots. In $(\mathbf{B})$, the same data are plotted as a function of the time interval from the sudden reduction in medium $\Psi$ to the time when $Y$ reached its minimal value at that medium $\Psi$ and was measured. Open circles (o) represent $\mathrm{Y}$ for roots in $0.1 \mathrm{~mm} \mathrm{CaCl}_{2}$, and closed circles $(\bullet)$, minimal $\mathrm{Y}$ after reduction in medium $\Psi$. The lines were fitted by eye. Cell turgor was measured with a pressure microprobe in the growth zone of primary roots (110 to $180 \mathrm{~mm}$ long, of 5- to 7-day-old seedlings) to determine Y. For details on the measurement of Y, the original paper should be consulted. From Frensch and Hsiao (1995). 
with respect to the loosening of the cell wall. Was adjustment in Y or in $\mathrm{m}$ more dominant in maintaining growth within a relatively narrow range as turgor varied? Separating out the effect of $Y$ from that of $m$ is not simple. In early studies, $\mathrm{Y}$ and $\mathrm{m}$ were evaluated from approximately linear plots of growth rate vs. $\psi_{\mathrm{p}}$. The growth rate was varied by varying tissue water status, and turgor pressure was calculated as the difference between measured $\Psi$ and $\psi_{\mathrm{s}}$ of the tissue. Under the assumption that $\mathrm{Y}$ and $\mathrm{m}$ remained the same for different growth rates, the slope of the plot was taken as $\mathrm{m}$, and the intercept with the $\mathrm{x}$-axis as Y. Later, a stress or turgor relaxation technique (Cosgrove, 1985) was used to evaluate $\mathrm{Y}$ and $\mathrm{m}$. Expansion of a growing organ or tissue was monitored after it was excised and deprived of a water source. The cell wall continued to relax under high turgor and the organ continued to expand as long as its $\psi_{\mathrm{p}}$ was greater than $\mathrm{Y}$, but expansion slowed and finally stopped when $\psi_{\mathrm{p}}=\mathrm{Y}$. By measuring $\psi_{\mathrm{p}}$ (Cosgrove, 1985) or calculating it from $\Psi$ and $\psi_{\mathrm{s}}$ measured at that point, $Y$ was determined and used, along with the growth rate, to calculate $\mathrm{m}$. A variation of this technique is the pressure block method (Cosgrove, 1987). Expansion of the excised tissue was monitored inside a pressure chamber and the pressure was raised until expansion just stopped. At that point the applied pressure is a measure of how much $\psi_{\mathrm{p}}$ exceeds $\mathrm{Y}$, or the growth-effective turgor. In view of the recent evidence that as water stress develops, $\mathrm{Y}$ and $\mathrm{m}$ may change within minutes in the direction that aids in the maintenance of growth, it is clear that these techniques determine most likely the lower limit of Y, not the $\mathrm{Y}$ at the moment of tissue excision or at the start of the pressure blocking. Skillful use of the pressure microprobe has enabled us (Frensch and Hsiao, 1994) to determine instantaneous Y during the transitional period from the time of stress imposition to the recovery in growth. The value of Y measured at the time of stress imposition was much higher than those evaluated by the older methods, and, consequently, the value of $m$ was also much higher. When growth resumed under the imposed stress, Y had declined substantially. For maize roots, Y did not decline when medium $\Psi$ was lowered by $0.1 \mathrm{MPa}$, and growth recovery was complete and effected by osmotic adjustment (Frensch and Hsiao, 1995). With further lowering of the medium $\Psi$, Y was reduced, and the reduction was maximal, $\approx 0.3 \mathrm{MPa}$, with a reduction in medium $\Psi$ of $0.6 \mathrm{MPa}$ (Fig. 3A). The reduction in Y occurred early, a few minutes after the imposition of water stress (Fig. 3B). Apparent $<20$ min was required to achieve the maximal reduction in $\mathrm{Y}$.

\section{SPATIAL PATTERN OF GROWTH REDUCTION AND OSMOTIC ADJUSTMENT UNDER WATER STRESS}

Are all cells in the growth zone of an organ affected similarly by water stress or do the effects vary with location and cell age? Time lapse photographs of maize roots marked on the surface at regular intervals and growing in vermiculite at different water potentials were digitized. Applying the principles of growth kinematics (Silk and Erickson, 1979), the local relative elongation rate for every millimeter of the root within the growth zone was computed. The results (Sharp et al., 1988) (Fig. 4A) show that the inhibition of growth by water stress was markedly dependent on location along the root. As $\Psi$ of the vermiculite was reduced progressively from -0.03 to $-1.60 \mathrm{MPa}$, more and more of the basal region of the normally growing zone of the root ceased to grow, and growth was restricted more and more to the apical region. In other words, the root growth zone shortened as water stress increased. Surprisingly, longitudinal growth in the apical $3 \mathrm{~mm}$ was unaffected regardless of the severity of stress. Shortening of the growth zone has also been observed in sorghum [Sorghum bicolor (L.) Moench] leaves under both water (Walker and Hsiao, 1993) and salinity (Berstein et al., 1993) stress, but not in water-stressed soybean hypocotyls (Meyers and Boyer, 1972).

In maize, radial growth was inhibited by water stress all along the growth zone length so that the root growing at lower $\Psi$ was thinner (Sharp et al., 1988). Thinner roots afford the advantage of exploring more soil volume for water for a given investment of carbon for root growth and maintenance. In the soil in the field, however, roots often grow thicker as the soil dries (Bengough and Mullins, 1990). The

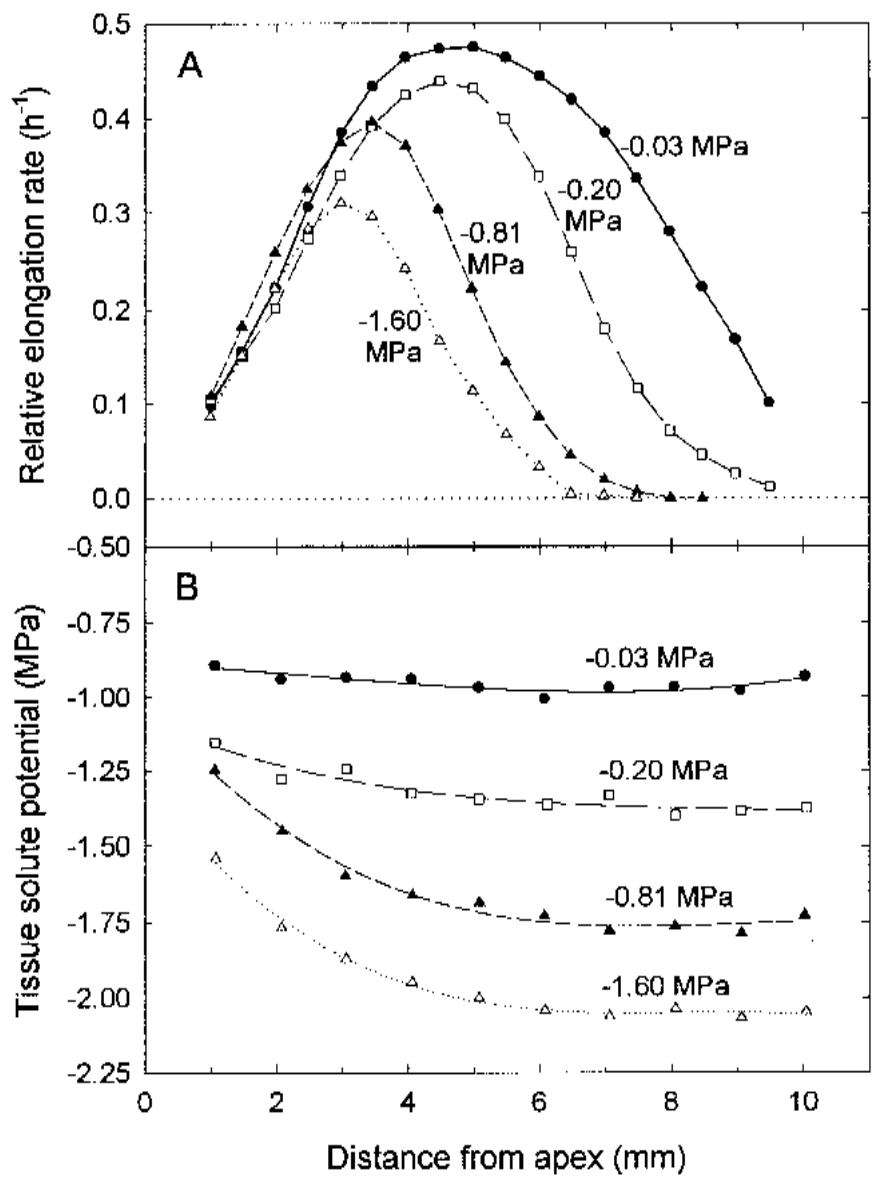

Fig. 4. Spatial distribution of longitudinal growth (A) and solute potential (B) in the apical $10 \mathrm{~mm}$ of primary root of etiolated maize seedlings as affected by water status. Growth is expressed as relative growth rate (increase in length per unit of length of each marked portion, per unit time). Seedlings were growing in vermiculite of different water contents and values of $\Psi$ (in $\mathrm{MPa})$ of the vermiculite are given in the figure next to each curve. The conditions were the same as for Fig. 1A. From Sharp et al. (1990).

marked increase in mechanical strength of many soils upon drying forces the root to grow thicker, and hence masking the thinning effect of water stress. Overall, the growth responses to water stress are amazingly complex, involving morphological as well as physiological, metabolic and macromolecular changes.

With the shortening of the root growth zone and the unchanged longitudinal growth rate of the apical $3 \mathrm{~mm}$ at low $\Psi$, one might expect more osmotic adjustment in the apical $3 \mathrm{~mm}$. It turned out that the reverse was true. Solute potential was constant along the growth zone of well-watered maize seedling roots. Sharp et al. (1990) found that with more and more water stress, the osmotic adjustment became stronger and stronger, but more occurred in the basal than in the apical region (Fig. 4B). When the medium $\Psi$ was reduced from $-0.03 \mathrm{MPa}$ to $-1.60 \mathrm{MPa}, \psi_{\mathrm{s}}$ of the basal region was reduced from -0.96 to -2.05 $\mathrm{MPa}$, whereas $\psi_{\mathrm{s}}$ at a distance 2 and $3 \mathrm{~mm}$ from the apex was reduced only to $-1.76 \mathrm{MPa}$ and $-1.87 \mathrm{MPa}$, respectively (Fig. 4B). Yet longitudinal growth in the apical $3 \mathrm{~mm}$ was not inhibited (Fig. 4A), reflecting the strong ability of that region to adjust the loosening ability of its cell wall. Interestingly, there was no increase in the production or importation of osmotica into the growth zone to account for the osmotic adjustment, whether in the basal or apical region. Instead, the reduced rate of solute dilution by growth, along with the reduction in root diameter, accounted for the osmotic adjustment in the roots growing at low $\Psi$ (Sharp et al., 1990). On the other hand, evidence based on the differential behavior of hexose and potassium as osmotica indicated that the osmotic adjustment was not totally passive (Sharp et al., 1990). 


\section{COMPARING LEAF AND ROOT GROWTH UNDER WATER STRESS IN TERMS OF THE LOCKHART EQUATION}

Detailed time courses of changes in turgor and growth rate upon stepwise changes in leaf water status are rare. For the situation of slowly developing water stress, Michelena and Boyer (1982) measured growth and water status of maize leaves once a day and found that growth zone turgor was completely maintained by osmotic adjustment, but the growth rate slowed and eventually dropped to zero as water stress became more severe. In a follow-up study, Van Volkenburgh and Boyer (1985) found that growth zone turgor was maintained essentially constant throughout the day, but growth slowed in the afternoon more than in the morning as stress developed. Compared with leaves of recently watered plants, stressed leaves acidified their growth zone apoplast more slowly and had a higher surface $\mathrm{pH}$. The authors concluded that extensibility of the cell wall might have been reduced by water stress and reduced wall acidification. There were uncertainties, however. Although differences in wall extension were measured in vitro on leaf segments boiled in methanol, effects on yield threshold could not be separated from that on extensibility (m). In addition, the shortening of the growth zone was not known at that time and might have accounted partly for the reduced growth at apparently the same turgor. Further, as was the standard practice in studies of expansive growth of higher plants at that time, turgor was calculated as the difference between $\Psi$ and $\psi_{\text {s }}$, measured by thermocouple psychrometry. The time required for equilibration of the growing tissue in the psychrometer was $3 \mathrm{~h}$ or more, sufficiently long to allow full or nearly full relaxation of the cell wall (Cosgrove, 1985). Consequently, the calculated turgor was most likely lower than the true value at the time of sampling, and was reduced to the value of adjusted $\mathrm{Y}$ in these early studies. The adjustment in $\mathrm{Y}$ would be greater for the leaves of high water status and faster growth rate, and the lower limit of adjusted $\mathrm{Y}$ may be very similar among growing leaves differing in water potential. Therefore the unchanging turgor at different leaf $\Psi$ may be an artifact of the method of measurement. Nonetheless, the early conclusion that growth of leaves was reduced in spite of turgor maintenance appears valid, since Hsiao and Jing (1987) also found in a field study the complete maintenance of turgor in the growth zone of sorghum leaves but a slower growth rate under mild water stress. Hsiao and Jing (1987) measured $\Psi$ of the growth zone with the Shardakov dye method (Slavik, 1974) at $5{ }^{\circ} \mathrm{C}$ using an equilibration time of less than $10 \mathrm{~min}$. The low temperature and short equilibration time should have eliminated the wall relaxation error. For sorghum, the slower growth in spite of the full maintenance of turgor was probably due to a shortening of the leaf growth zone under water stress (Walker and Hsiao, 1993).

Again using the Shardakov method, Hsiao and Jing (1987) investigated the changes in maize leaf growth and turgor at 15 min intervals upon a stepping down in medium $\Psi$ of $0.25 \mathrm{MPa}$. Growth stopped for $\approx 15 \mathrm{~min}$, then began slowly to recover as $\psi_{\mathrm{p}}$ began to recover through osmotic adjustment (Fig. 5). This is in contrast to the recovery in turgor and growth within minutes after the $0.42 \mathrm{MPa}$ down-step for roots (Fig. 2). After $75 \mathrm{~min}$, turgor had recovered to the level prior to stress imposition, but growth remained partly inhibited. These results indicate that under water stress, wall loosening ability in the leaves was reduced (an increase in $Y$ or a reduction in $\mathrm{m}$ ), whereas wall loosening ability in roots was enhanced as evinced by the reduction in Y (Fig. 3).

Leaves of the Gramineae are often chosen for studies because their growth is predominantly one-dimensional with clear gradients in the longitudinal direction. On the other hand, their growth zone is wrapped in older leaves and difficult to reach with a pressure microprobe. Thus the initial study (Shackel et al., 1987) of turgor and growth using a pressure microprobe was on leaves of a dicot, grape (Vitis vinifera L.). A detailed leaf study of effects of water stress with the microprobe is on another dicot, Begonia argenteo-guttata L. (Serpe and Matthews, 1992). Turgor in the epidermal cells near the central midvein was measured. With a down-step in root medium $\Psi$ of 0.2 or $0.3 \mathrm{MPa}$, growth stopped and turgor dropped. Growth remained nil for $25 \mathrm{~min}$ or more and then recovered gradually to reach a slower but steady rate. Turgor, however, did not recover measurably and remained reduced over the 2-h stress period. Hence, no osmotic adjustment occurred in the Begonia leaves and the resumption in growth under water stress was the result of enhanced extending ability of the cell wall.

We have obtained similar results with maize leaves (A. Thomas and T.C. Hsiao, unpublished data). A window was carefully cut in the coleoptile sheathing the first leaf of the seedling to expose the growth zone of the leaf for the measurement of turgor with the pressure microprobe. Upon a $0.4-\mathrm{MPa}$ down-step of root medium $\Psi$, growth stopped within minutes and remained nil for approximately $1 \mathrm{~h}$, before resuming at a very slow rate. Turgor in the growth zone of the leaf took $\approx 0.5 \mathrm{~h}$ to decline, by nearly $0.3 \mathrm{MPa}$, to the lowest point after the downstep in $\Psi$ of the rooting medium. Thereafter turgor increased very slowly. The slow decrease in turgor after the down-step was presumably the result of slow transpiration relative to the water storage ("buffering") capacity of the tissue. The seedling had only one leaf, still partially folded, and consequently must have transpired at a low rate. In view of the recovery in turgor in Fig. 5, the very slow turgor recovery in our pressure microprobe study was a surprise. It is probable that osmotic adjustment for a part of the turgor recovery was not obvious because it took place during the first $0.5 \mathrm{~h}$ and was masked by the overall decline in turgor associated with the gradual reduction in leaf $\Psi$. The fact that turgor recovered fully in $<2 \mathrm{~h}$ in Fig. 5 but not in this study could be the result of a difference in the supply of assimilate or osmotica. In the former case the plant had five well-lit leaves, whereas in the latter, the plant had one unfolding leaf that was just beginning to develop its photosynthetic capacity. Note that the quick recovery in turgor and growth in maize roots after a down-step in $\Psi$ took place regardless of whether the plant already had several

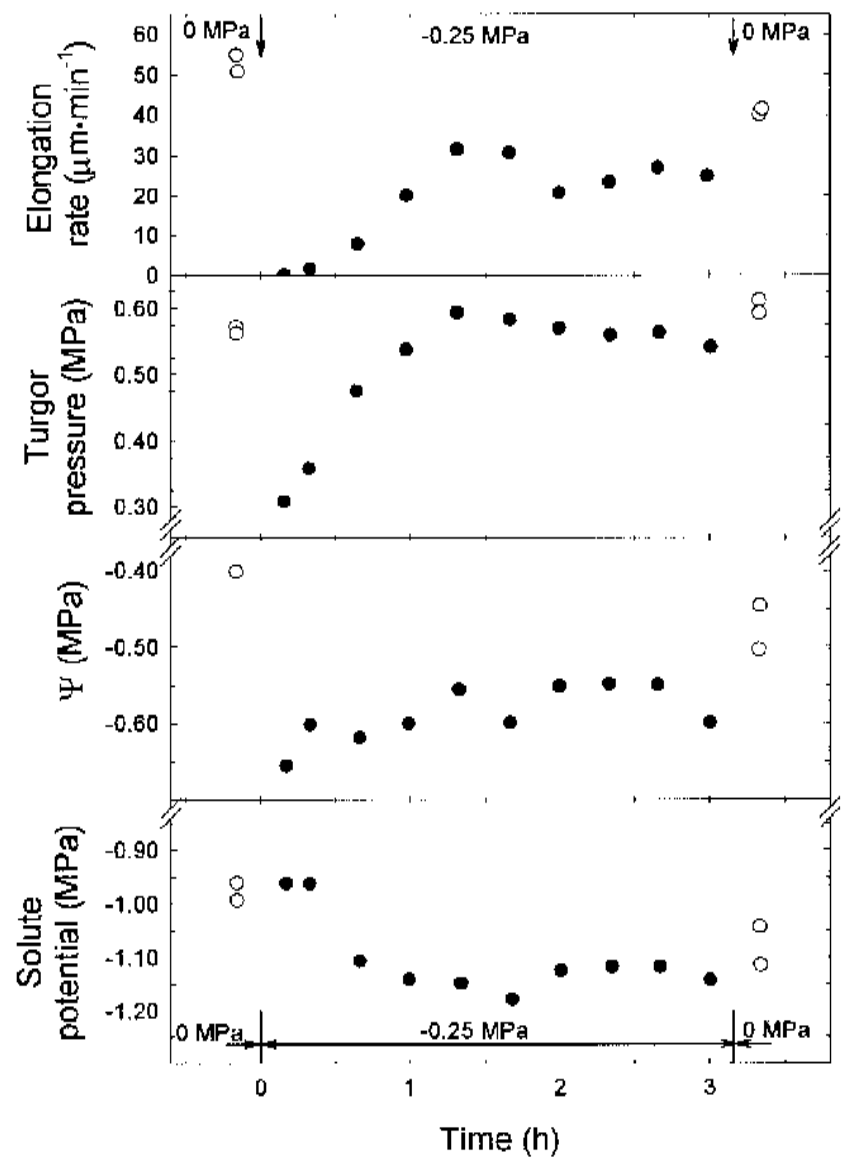

Fig. 5. Changes in longitudinal growth rate and water potential and its components in the growing fifth leaf of maize upon changes in root medium $\Psi$. Medium $\Psi$ was changed stepwise by changing between $0.1 \mathrm{~mm} \mathrm{CaCl}_{2}$ solutions with and without $-0.25 \mathrm{MPa}$ of Carbowax $6000^{\circledR}$ at the times indicated by the downward arrows. Data for $0.1 \mathrm{~mm} \mathrm{CaCl}_{2}$ medium are given as open circles (o). Growth rate was measured by LVDT. The conditions and procedures were essentially those of the experiment depicted in Fig. 1B. From Hsiao and Jing (1987). 
photosynthetically active leaves (Frensch and Hsiao, 1995) or was merely an etiolated seedling (Fig. 2).

Overall, there is a sharp contrast between the root and the leaf in their responses to water stress. The root adjusts osmotically and its turgor recovers quickly, but only partially, under water stress. With the rapid lowering of $\mathrm{Y}$, and, possibly increases in $\mathrm{m}$, root elongation can recover fully under mild water stress and at reduced turgor. Root growth is maintained partially even down to the permanent wilting point and beyond. The leaf osmotically adjusts either slowly (Fig. 5) or not at all (Serpe and Matthews, 1992). The loosening ability of its cell wall is reduced (Fig. 5) or at least not markedly enhanced under water stress. Consequently its growth is much more inhibited by water stress than is that of the root.

\section{ROLES OF ABA, EXPANSINS, AND OTHER CATALYTIC PROTEINS}

Under water stress, ABA increases in both leaves and roots (reviewed by Hsiao, 1973) and more ABA is transported from roots to leaves (Davies and Zhang, 1991; Zhang and Davies, 1990). Loosening ability of the growing cell wall is well known to be promoted by auxins (Cleland, 1971; Green and Cummins, 1974; Nakahori et al., 1991) and also affected by ABA. Convincing evidence was obtained by Sharp and coworkers (Sharp et al., 1994; Spollen et al., 1993) indicating that ABA maintains root growth while inhibiting shoot growth in maize at low $\Psi$. Their experiments were designed to look at more or less steady growth, involving growth over periods of many hours to days. An inhibitor of carotenoid synthesis (and therefore of ABA synthesis), fluridone \{1-methyl-3 phenyl-5-[3-(trifluoromethyl] phenyl]-4-(1H)pyridinone $\}$, had little effect on root or shoot elongation of etiolated seedlings growing at high $\Psi(-0.03 \mathrm{MPa})$, but depressed root elongation and promoted shoot elongation at low $\Psi(-1.6 \mathrm{MPa}$ for roots and $-0.3 \mathrm{MPa}$ for shoot) (Saab et al., 1990). The behavior of a mutant of maize deficient in $\mathrm{ABA}, v p 5$, was very similar to that of the wild type treated with fluridone. Root elongation was more inhibited and shoot elongation was better maintained in $v p 5$ than in the wild type at low $\Psi$. In the latter, the concentration of endogenous ABA increased markedly at low $\Psi$ and the increase was suppressed substantially by fluridone. Under water stress ABA concentration was the highest in the apical $3 \mathrm{~mm}$ where the relative elongation rate was fully maintained (Saab et al., 1992). Exogenous ABA at the appropriate concentration overcomes the effect of fluridone on growth of root and shoot at low $\Psi$, and modified the growth of $v p 5$ mutant at low $\Psi$ to resemble that of the wild type (Sharp et al., 1994). On the other hand, despite the fact that endogenous $\mathrm{ABA}$ is very low at high $\Psi$, adding $\mathrm{ABA}$ to the growth medium inhibited root growth. Taken together, these results provide strong evidence that ABA plays a central role in orchestrating the differential long-term growth responses to water stress of root and shoot. What is not clear is whether ABA is similarly involved in the rapid changes in the growth parameters of the Lockhart equation in the two organs briefly reviewed above. Those changes were very rapid, taking place within minutes or a fraction of an hour after a down-step in $\Psi$. The increase in tissue ABA effected by water stress and the increased transport of ABA from root to shoot may take considerably longer (Hsiao and Bradford, 1983), and cannot be easily invoked to explain the early responses.

The molecular basis of wall extending ability have long been the subject of investigation, speculation, and modeling (Passioura and Fry, 1992). The acid growth theory of cell expansion is now well established and applicable to most species (Rayle and Cleland, 1992). Over the last decade Cosgrove and colleagues have developed strong evidence for the existence in the cell wall of a class of proteins named expansins, which act as catalysts in promoting wall expansion (reviewed by Cosgrove, 1998). There is some evidence suggesting that expansins act by weakening hydrogen bonding among wall polymers to promote wall "loosening," especially at low pH (McQueen-Mason and Cosgrove, 1994). An intriguing study was carried out by Wu et al. (1996) on expansins in relation to water stress. They used isolated cell walls from maize roots and evaluated their acid-induced extension by stretching them with an extensometer. Compared with roots grown at $\Psi$ of $-0.03 \mathrm{MPa}$, acid-induced extension was markedly increased in the apical $5 \mathrm{~mm}$ and mostly eliminated in the 5 to $10 \mathrm{~mm}$ region of the roots grown at $-1.6 \mathrm{MPa}$. This is consistent with the maintenance of growth at the region adjacent to the apex and the shortening of the growth zone under water stress. Crude wall protein extracted from low $\Psi$ roots contained more expansin activity than that from high $\Psi$ roots when applied to cucumber (Cucumis sativa L.) cell wall in extensometer assays, and also contained more expansin proteins, as indicated by Western blots. Response to growth-promotive effect of expansins was greater in the apical $5 \mathrm{~mm}$ and was totally absent in the 5 to $10 \mathrm{~mm}$ region of the roots grown at low $\Psi$. Thus, both the amount of expansins in the cell wall and the responsiveness of the wall to expansins were altered by water stress in a way that facilitates root growth at low $\Psi$. Not yet known is whether at low $\Psi$ expansins undergo changes in shoots in the opposite direction, to explain the differential effect of water stress on roots vs. leaves.

Other changes in wall components and enzymes occur in plants under water stress. For a more comprehensive examination, the pertinent papers in this volume and in an early (Wang et al., 1994) and an upcoming (Sept. 2000) issue of Journal of Experimental Botany should be consulted. Other papers (Conley et al., 1997; Saab et al., 1995; Wu et al., 1994) may also be of interest.

\section{ECOPHYSIOLOGICAL AND PRODUCTIVITY IMPLICATIONS}

In the absence of rain and irrigation, root expansion to explore new soil volume for water is critical for the continued function, growth, and survival of plants. Hydraulic conductivity of the soil declines nearly exponentially with decreases in soil water content. Thus in soils with water content at field capacity or lower, water movement is slow and the roots must grow into the wetter parts of the soil to maintain adequate water uptake. This is well illustrated in Fig. 6, which depicts the development of the root system in terms of root length density (length of root per volume of soil) and the extraction of soil water by a maize crop growing on water stored in the soil without substantial rainfall during the growing season. As the crop grew, the root system deepened and root density increased in each soil depth layer with time (Fig. 6A). Shown in Fig. 6B is the profile of mean rates of soil water extraction by roots at each depth layer at different times. Comparison of the root length density profile with the water extraction profile at any given date indicates that extraction started only after root length density in that depth layer became substantial, and no extraction occurred before roots grew into that depth layer. In fact, the rate of water extraction was closely correlated with root length density (Fig. 7).

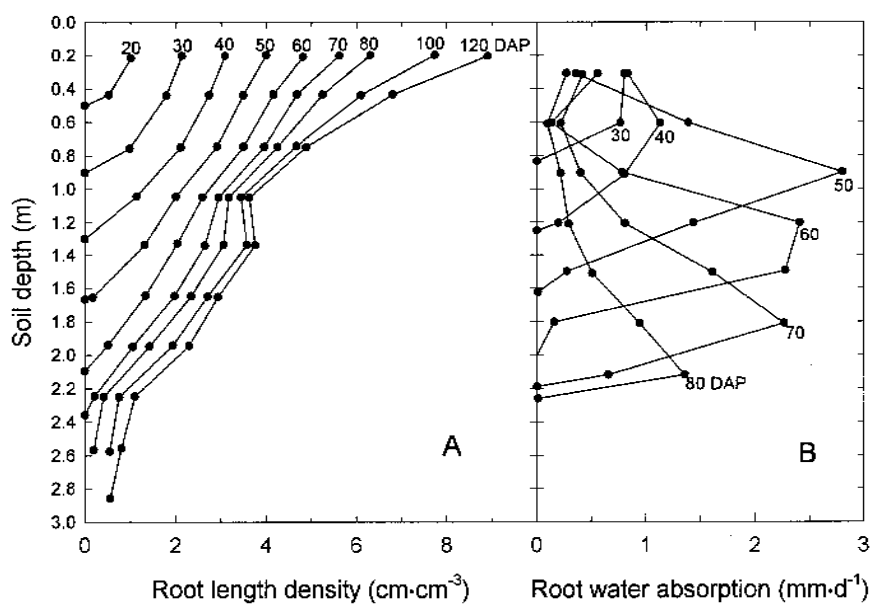

Fig. 6. Estimated root length density (A) and computed root water absorption rate (B) of a maize crop in each 300-mm layer of soil at different times after planting. Numbers on the curves denote numbers of days after planting (DAP). Root length density was measured by the line interception method on soil core samples. Water absorption was calculated by water balance with soil water content measured by a neutron probe. The crop was grown without irrigation on a Yolo clay loam soil in Davis, Calif. The soil was well wetted to $3 \mathrm{~m}$ at planting time and received only $\approx 1 \mathrm{~cm}$ of water as rain during the growing cycle. From Hsiao et al. (1976). 


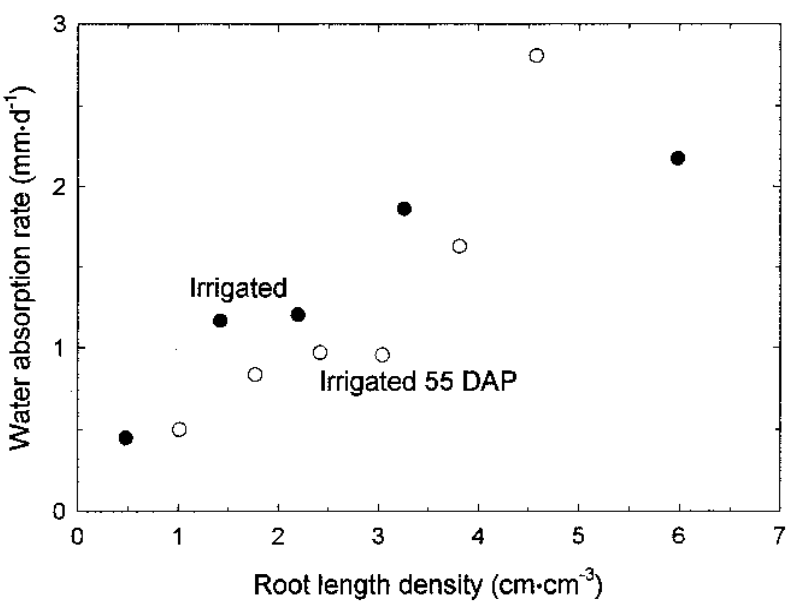

Fig. 7. Computed water absorption rate by maize roots as related to root length density, in moist Yolo clay loam soil. Values are means of various $300-\mathrm{mm}$ soil depth layers for the period of 62-74 $\mathrm{d}$ after planting and represent two treatments, one regularly irrigated $(\bullet)$ and one irrigated regularly beginning $55 \mathrm{~d}$ after planting (DAP) (o). From Hsiao et al. (1976).

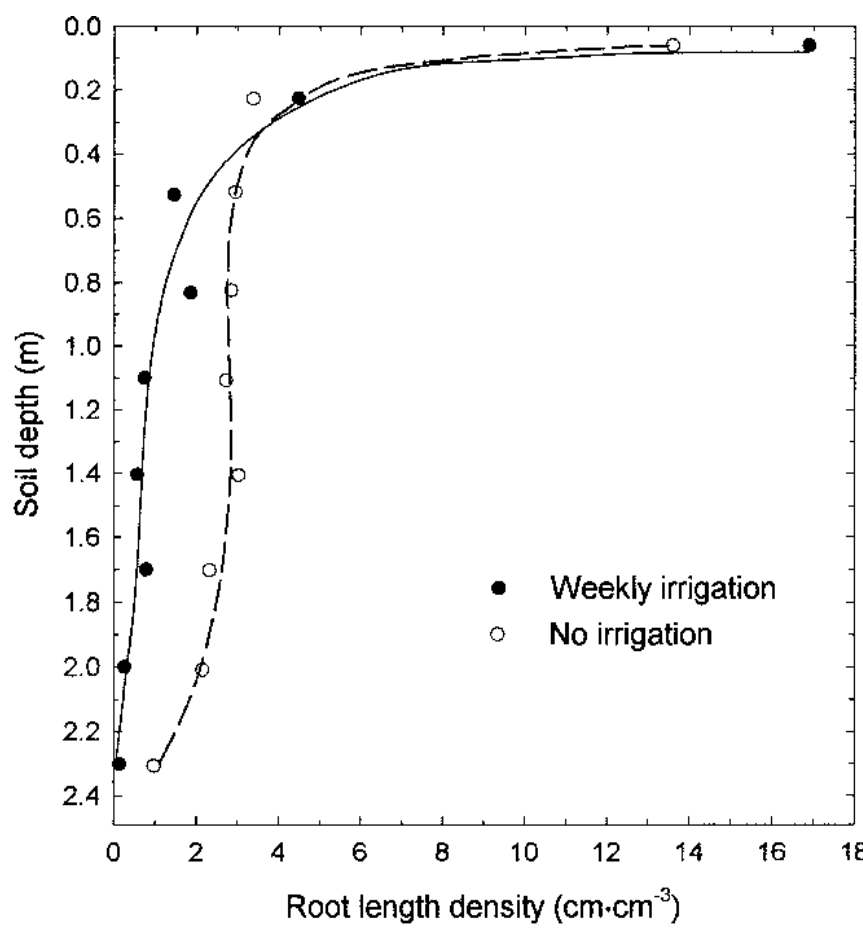

Fig. 8. Effects of irrigation on maize root distribution at plant maturity in various depth layers of a Yolo clay loam soil. The crop was planted after a deep irrigation and received virtually no rain during the growing cycle. One treatment was irrigated weekly and the other was not irrigated. Lines are fitted by eye. Original data of J.D. Vega and D.W. Henderson, reproduced from Hsiao and Acevedo (1974).

In the field the maintenance of root growth as water stress develops has two facets. One is the physiological one discussed above- that of rapid but partial osmotic adjustment and the enhancement in loosening ability of the cell wall. The other facet is the interaction of growth with the soil environment. In spite of its resistance to reductions in $\Psi$, root growth is faster at higher values of $\Psi$ (Fig. 1A). Consequently roots would grow more in the wetter parts of the soil. This behavior is illustrated in Fig. 8, which depicts the profiles of root length density of maize under irrigated and dryland (unirrigated) conditions. Without irrigation and over a season, roots proliferated much more in the wetter, lower depth layers, and growth in the drier, upper layers was limited in comparison with the well-irrigated treatment. Hence, not only was root growth favored relative to shoot growth, the distribution of roots was also shifted to the wetter soil making more effective use

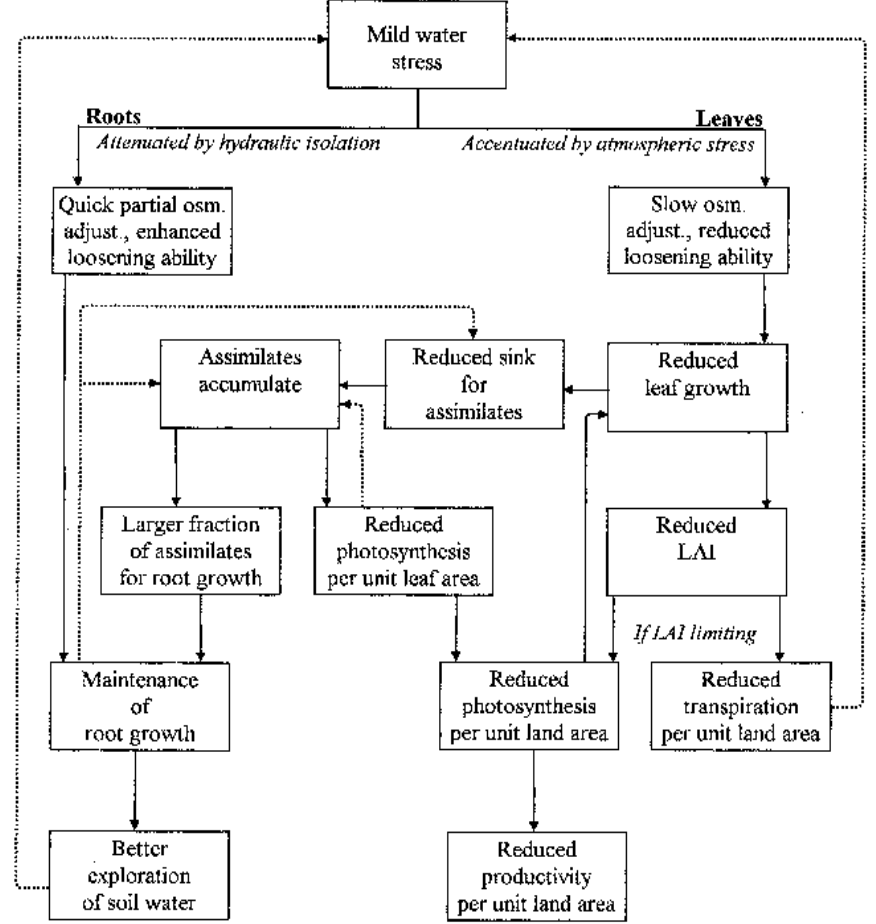

Fig. 9. Outline of generalized responses and adaptation of crops in the field to mild water stress, with emphasis on expansive growth of roots vs. leaves. The more direct effects of water stress on growth are based the parameters in the Lockhart's equation, with osmotic adjustment impacting $\psi_{p}$ and wall loosening ability reflected in $\mathrm{Y}$ and $\mathrm{m}$. Dotted lines with arrows indicate negative feedback effects. Considerations of water availability, transpiration, and productivity are on the basis of per unit land area. In the field the development of water stress causes first a slowing down in leaf growth while photosynthesis per unit leaf area remains unaffected because stress is not yet severe enough. Photosynthesis per unit land area, however, is already reduced because of the smaller canopy cover and reduced PAR interception and absorption. The water stress considered is assumed to be mild enough not to have significant direct impact on stomata, or on transpiration and photosynthesis per unit effective leaf area. Photosynthesis per unit leaf area, however, is depicted to be susceptible to inhibition by accumulated assimilates in the leaf. Note that the negative effect of water stress on leaf growth and productivity compounds with time because reduced leaf growth reduces photosynthetic surface per unit land area, which further reduces growth.

of each mm of root length. This preferential growth into the wetter parts of the soil is further aided by special anatomical and hydraulic features of the root apex. The growing region of the maize root is not well connected to the mature region by fully differentiated xylem (McCulley, 1995; St. Aubin et al., 1986). Frensch and Hsiao (1993) have shown that the apical region of the root is largely isolated hydraulically from the more basal part with a fully developed xylem system that supplies water to the shoot. As the root grows, the apical growing region and the newly matured, basal, water-absorbing and conducting region move continuously as one unit through the soil, with the apical region leading the way into new soil moisture and hydraulically separated from the basal region. Therefore, $\Psi$ of the apical region remains relatively high and most of the water it absorbs is presumably retained for growth, despite the strong tension that may develop in the mature xylem vessels of the basal region under conditions of high transpiration. In this way water is available to the shoot only after the water requirement of the apical region of the root is satisfied.

Leaf growth also has a facet that is determined by interaction with its environment, that of the atmosphere. Under conditions of high evaporative demand (high radiation, temperature, and wind, and low humidity), transpirational loss of water usually increases, leaf $\Psi$ is reduced, and the difference in $\Psi$ between the roots and the growing leaf is accentuated. With mild water stress, stomata usually remain open, so $\Psi$ of the leaf is lower for a given soil $\Psi$ when evaporative demand 
and transpiration are high than when they are low. Overall, the interaction of leaves with the atmosphere induces or accentuates water stress in the leaf growth zone, in contrast to the interaction of the growing root apices with the soil, which attenuates the effects of water stress developing in the more mature parts of the roots and in the shoot.

The contrasting behavior of root and leaf growth under mild water stress and the implications for adaptation, water use, and productivity are summarized in a flow diagram in Fig. 9. Leaves and roots compete as sinks for photosynthetic assimilates in maintaining their growth. Mild water stress, not yet severe enough to inhibit stomatal conductance and photosynthesis per unit leaf area, would reduce leaf growth (Bradford and Hsiao, 1982) and its role as a sink for assimilates, leaving a larger fraction of assimilates available for root growth. If enough assimilates accumulate in the leaves, however, photosynthesis per unit leaf area may be inhibited (Fig. 9). This potential for "feedback" inhibition is increased if nitrogen (Stitt and Schulze, 1994) or phosphorus (Riviere-Rolland and Betshe, 1996) nutrition is not ample.

With leaf expansion reduced by mild water stress, the increment in leaf area index (LAI) and the development of foliage canopy slow. If this occurs when the canopy does not yet completely cover the ground and intercept all the incident photosynthetically active radiation, photosynthesis per unit land area would be less, although water stress is not severe enough to inhibit directly photosynthesis. Additional effect could come from photosynthesis being inhibited indirectly if assimilates accumulate sufficiently. The resulting reduction in primary productivity of the crop could be quite substantial if the mild water stress lasts for many days. The effect of a small difference in daily leaf growth compounds with time, in a manner analogous to how a small difference in interest rate compounds with time into a large difference in interest income (Hsiao, 1993). On the other hand, the restriction in canopy development would also reduce transpiration per unit land area and the effect would also compound with time. That would lead to a slowing down in the rate of development of water stress (right dotted line, Fig. 9).

With roots under water stress the situation is quite different. Quick but partial osmotic adjustment and enhanced loosening ability of the cell wall, aided by the hydraulic isolation of the growing apex and the enhanced assimilate supply as the result of reduced leaf growth, permit the maintenance of growth of roots, at least partially. The continuous growth of roots requires a continuous assimilate supply and minimizes assimilate accumulation and feedback inhibition of photosynthesis. Most importantly, it provides for the continuous exploration of new soil volume for water to partially ameliorate water stress (left dotted line, Fig. 9). By combining the ameliorating effects of leaf and root growth on the development of water stress, over the long term the plant can adjust its canopy size so as to nearly match its transpiration loss with water supply from the root system, provided that the soil water storage capacity is high (Hsiao et al., 1976).

\section{Literature Cited}

Acevedo, E., T.C. Hsiao, and D.W. Henderson. 1971. Immediate and subsequent growth responses of maize leaves to changes in water status. Plant Physiol. 48:631-636.

Bengough, A.G. and C.E. Mullins. 1990. Mechanical impedance to root growth, a review of experimental techniques and root growth responses. J. Soil Sci. 41:341-358

Bernstein, N., W.K. Silk, and A. Läuchli. 1993. Growth and development of sorghum leaves under conditions of $\mathrm{NaC} 1$ stress. Spatial and temporal aspects of leaf growth inhibition. Planta 191:433-439.

Boyer, J.S. 1968. Relationship of water potential to growth of leaves. Plant Physiol. 43:1056-1062.

Bradford, K.J. and T.C. Hsiao. 1982. Physiological responses to moderate water stress, p. 263-324. In: O.L. Lange, P.S. Nobel, C.B. Osmond, and H. Ziegler (eds.). Physiological plant ecology II. Water relations and carbon assimilation. Springer-Verlag, Berlin.

Cleland, R.E. 1971. Cell wall extension. Annu. Rev. Plant Physiol. 22:197-222.

Conley, T.R., R.E. Sharp, and J.C. Walker. 1997. Water deficit rapidly stimulates the activity of a protein kinase in the elongation zone of the maize primary root. Plant Physiol. 113:219-226.

Cosgrove, D.J. 1985. Cell wall yield properties of growing tissue. Evaluation by in vivo stress relaxation. Plant Physiol. 78:347-356.

Cosgrove, D.J. 1987. Wall relaxation in growing stems: Comparison of four species and assessment of measurement techniques. Planta 171:266-278.

Cosgrove, D.J. 1998. Cell wall loosening by expansins. Plant Physiol. 118:333339.

Cosgrove, D.J., E. Van Volkenburgh, and R.E. Cleland. 1984. Stress relaxation of cell walls and the yield threshold for growth: Demonstration and measurement by micro-pressure probe and psychrometer techniques. Planta $162: 46-54$

Davies, W.J. and J. Zhang. 1991. Root signals and the regulation of growth and development of plants in drying soil. Annu. Rev. Plant Physiol. Plant Mol. Biol. 42:55-76.

Frensch, J. and T.C. Hsiao. 1993. Hydraulic propagation of pressure along immature and mature xylem vessels of roots of Zea mays measured by pressure probe techniques. Planta 190:263-270.

Frensch, J. and T.C. Hsiao. 1994. Transient responses of cell turgor and growth of maize roots as affected by changes in water potential. Plant Physiol. 104:247-254.

Frensch, J. and T.C. Hsiao. 1995. Rapid response of the yield threshold and turgor regulation during adjustment of root growth to water stress in Zea mays. Plant Physiol. 108:303-312.

Greacen, E.L. and J.S. Oh. 1972. Physics of root growth. Nature New Biol. $235: 24-25$

Green, P.B. 1968. Growth physics in Nitella: A method for continuous in vivo analysis of extensibility based on a micro-manometer technique for turgor pressure. Plant Physiol. 43:1169-1184.

Green, P.B. and W.R. Cummins. 1974. Growth rate and turgor pressure: Auxin effect studied with an automated apparatus for single coleoptiles. Plant Physiol. 54:863-869.

Hsiao, T.C. 1973. Plant responses to water stress. Annu. Rev. Plant Physiol. 24:519-570.

Hsiao, T.C. 1993. Growth and productivity of crops in relation to water status. Acta Hort. 335:137-148.

Hsiao, T.C. and E. Acevedo. 1974. Plant responses to water deficits, water-use efficiency, and drought resistance. Agr. Meteorol. 14:59-84.

Hsiao, T.C., E. Acevedo, E. Fereres, and D.W. Henderson. 1976. Water stress, growth, and osmotic adjustment. Phil. Trans. Royal Soc. London Ser. B 273:479-500.

Hsiao, T.C. and K.J. Bradford. 1983. Physiological consequences of cellular water deficits, p. 227-265. In: H.M. Taylor, W.R. Jordan, and T.R. Sinclair (eds.). Limitations to efficient water use in crop production. Amer. Soc. Agron., Madison, Wis.

Hsiao, T.C. and J. Jing. 1987. Leaf growth in response to water deficits, p. 180192. In: D.J. Cosgrove and D.P. Knievel (eds.). Physiology of cell expansion during plant growth. Amer. Soc. Plant Physiol., Rockville, Md.

Kuzmanoff, K.M. and M.L. Evans. 1981. Kinetics of adaptation to asmotic stress in lentil (Lens culinaris med.) roots. Plant Physiol. 68:244-247.

Lockhart, J.A. 1965. Cell extension, p. 826-849. In: J. Bonner and J.E. Varner (eds.). Plant biochemistry. Academic, New York.

McCully, M.E. 1995. How do real roots work? Some new views of root structure. Plant Physiol. 109:1-6.

McQueen-Mason, S. and D.J. Cosgrove. 1994. Disruption of hydrogen bonding between wall polymers by proteins that induce plant wall extension. Proc. Natl. Acad. Sci. U.S.A. 91:6574-6578.

Meyers, R.F. and J.S. Boyer. 1972. Sensitivity of cell division and cell elongation to low water potentials in soybean hypocotyls. Planta 108:7787.

Michelena, V.A. and J.S. Boyer. 1982. Complete turgor maintenance at low water potentials in the elongating region of maize leaves. Plant Physiol. 69:1145-1149.

Nakahori, K., K. Katou, and H. Okamoto. 1991. Auxin changes both the extensibility and the yield theshold of the cell wall of Vigna hypocotyls. Plant Cell Physiol. 32:121-129.

Nonami, H. and J.S. Boyer. 1990. Primary events regulating stem growth at low water potentials. Plant Physiol. 93:1601-1609.

Nonami, H., Y. Wu, and J.S. Boyer. 1997. Decreased growth-induced water potential. A primary cause of growth inhibition at low water potentials. Plant Physiol. 114:501-509

Passioura, J.B. and S.C. Fry. 1992. Turgor and cell expansion: Beyond the Lockhart equation. Aust. J. Plant Physiol. 19:565-576.

Rayle, D.L. and R.E. Cleland. 1992. The acid growth theory of auxin-induced cell elongation is alive and well. Plant Physiol. 99:1271-1274.

Riviere-Rolland, H. and T. Betsche. 1996. Adaptation of pea to elevated atmospheric $\mathrm{CO}_{2}$ : Rubisco, phosphoenolpyruvate carboxylase and chloroplast phosphate translocator at different levels of nitrogen and phosphorus nutrition. Plant Cell Environ. 19:109-117.

Saab, I.N., T.H. D. Ho, and R.E. Sharp. 1995. Translatable RNA populations associated with maintenance of primary root elongation and inhibition of mesocotyl elongation by abscisic acid in maize seedlings at low water potentials. Plant Physiol. 109:593-601.

Saab, I.N., R.E. Sharp, and J. Pritchard. 1992. Effect of inhibition of ABA 


\section{Colloquium}

accumulation on the spatial distribution of elongation in the primary root and mesocotyl of maize at low water potentials. Plant Physiol. 99:26-33.

Saab, I.N., R.E. Sharp, J. Pritchard, and G.S. Voetberg. 1990. Increased endogenous abscisic acid maintains primary root growth and inhibits shoot growth at low water potentials. Plant Physiol. 93:1329-1336.

Serpe, M. and M. Matthews. 1992. Rapid changes in cell wall yielding of elongating Begonia argenteo-guttata L. Leaves in response to changes in plant water status. Plant Physiol. 100:1852-1857.

Shackel, K.A., M.A. Matthews, and J.C. Morrison. 1987. Dynamic relation between expansion and cellular turgor in growing grape (Vitis vinifera L.) leaves. Plant Physiol. 84:1166-1171.

Sharp, R.E., T.C. Hsiao, and W.K. Silk. 1990. Growth of the maize primary root at low water potential. II. The role of growth and deposition of hexose and potassium in osmotic adjustment. Plant Physiol. 93:1337-1346.

Sharp, R.E., W.K. Silk, and T.C. Hsiao. 1988. Growth of the maize primary root at low water potentials. I. Spatial distribution of expansive growth. Plant Physiol. 87:50-57.

Sharp, R.E., Y. Wu, G.S. Voetberg, I.N. Saab, and M.E. LeNoble. 1994 Confirmation that abscisic acid accumulation is required for maize primary root elongation at low water potentials. J. Expt. Bot. 45:1743-1751.

Silk, W.K. and R.O. Erickson. 1979. Kinematics of plant growth. J. Theor. Biol. 76:481-501.

Slavik, B. 1974. Methods of studying plant water relations. Springer-Verlag, New York.

Spollen, W.G., R.E. Sharp, I.N. Saab, and Y. Wu. 1993. Regulation of cell expansion in roots and shoots at low water potentials, p. 37-52. In: J.A. C Smith and H. Griffiths (eds.). Water deficits: Plant responses from cell to community. Bios Scientific Publ., Oxford.
St. Aubin, G., M.J. Canny, and M.E. McCully. 1986. Living vessel elements in the late metaxylem of sheathed maize roots. Ann. Bot. 58:577-588.

Stitt, M. and D.-E. Schulze. 1994. Does Rubisco control the rate of photosynthesis and plant growth? An exercise in molecular ecophysiology. Plant Cell Environ. 17:465-487.

Van Volkenburgh, E. and J.S. Boyer. 1985. Inhibitory effects of water deficit on maize leaf elongation. Plant Physiol. 77:190-194.

Walker, S. and T.C. Hsiao. 1993. Osmoticum, water and dry matter deposition rates in the growth zone of sorghum leaves under water deficit conditions. Environ. Expt. Bot. 33:447-456

Wang, T. L., W.J. Davies, and C.J. Pollack (eds.). 1994. Growth in Planta. J. Expt. Bot. vol. 45 (Spec. issue).

Westgate, M.E. and J.S. Boyer. 1985. Osmotic adjustment and the inhibition of leaf, root, stem and silk growth at low water potentials in maize. Planta 164:540-549.

Wilson, J.B. 1988. A review of evidence on the control of shoot-root ratio, in relation to models. Ann. Bot. 61:433-449.

Wu, Y., R.E. Sharp, D.M. Durachko, and D.J. Cosgrove. 1996. Growth maintenance of the maize primary root at low water potentials involves increases in cell-wall extension properties, expansin activity, and wall susceptibility to expansins. Plant Physiol. 111:765-772.

Wu, Y., W.G. Spollen, R.E. Sharp, P.R. Hetherington, and S.C. Fry. 1994. Root growth maintenance at low water potentials. Increased activity of xyloglucan endotransglycosylase and its possible regulation by abscisic acid. Plant Physiol. 106:607-615.

Zhang, J. and W.J. Davies. 1990. Changes in the concentration of ABA in xylem sap as a function of changing soil water status can account for changes in leaf conductance and growth. Plant Cell Environ. 13:277-285. 